\title{
Post-Pliocene establishment of the present monsoonal climate in SW China: evidence from the late Pliocene Longmen megaflora
}

\author{
T. Su ${ }^{1,3}$, F. M. B. Jacques ${ }^{1}$, R. A. Spicer ${ }^{4,5}$, Y.-S. Liu ${ }^{6}$, Y.-J. Huang ${ }^{2}$, Y.-W. Xing ${ }^{7}$, and Z.-K. Zhou ${ }^{1,2}$ \\ ${ }^{1}$ Key Laboratory of Tropical Forest Ecology, Xishuangbanna Tropical Botanical Garden, Chinese Academy of Sciences, \\ Mengla 666303, China \\ ${ }^{2}$ Key Laboratory of Biodiversity and Biogeography, Kunming Institute of Botany, Chinese Academy of Sciences, \\ Kunming 650204, China \\ ${ }^{3}$ State Key Laboratory of Paleobiology and Stratigraphy, Nanjing Institute of Geology and Paleontology, \\ the Chinese Academy of Sciences, Nanjing 210008, China \\ ${ }^{4}$ Department of Earth and Environmental Sciences, Centre for Earth, Planetary, Space and Astronomical Research, \\ The Open University, Milton Keynes, MK7 6AA, UK \\ ${ }^{5}$ Institute of Botany, Chinese Academy of Sciences, Beijing 100093, China \\ ${ }^{6}$ Department of Biological Sciences, P.O. Box 70703, East Tennessee State University, Johnson City, \\ Tennessee 37614-1710, USA \\ ${ }^{7}$ Institute of Systematic Botany, University of Zürich, Zürich, 8008, Switzerland \\ Correspondence to: Z.-K. Zhou (zhouzk@xtbg.ac.cn)
}

Received: 16 January 2013 - Published in Clim. Past Discuss.: 2 April 2013

Revised: 22 June 2013 - Accepted: 1 July 2013 - Published: 14 August 2013

\begin{abstract}
The paleoclimate of the late Pliocene Longmen flora from Yongping County located at the southeastern boundary of the Qinghai-Tibet Plateau was reconstructed using two leaf-physiognomy-based methods, i.e., leaf margin analysis (LMA) and Climate Leaf Analysis Multivariate Program (CLAMP), to understand the paleoclimate condition and geographical pattern of monsoonal climate in southwestern China during the late Pliocene. The mean annual temperatures (MATs) estimated by LMA and CLAMP are $17.4 \pm 3.3^{\circ} \mathrm{C}$ and $17.4 \pm 1.3^{\circ} \mathrm{C}$, respectively, compared with $15.9^{\circ} \mathrm{C}$ at present. Meanwhile, the growing season precipitation (GSP) estimated by CLAMP is $1735.5 \pm 217.7 \mathrm{~mm}$ in the Longmen flora, compared with $986.9 \mathrm{~mm}$ nowadays. The calculated monsoon intensity index (MSI) of the Longmen flora is significantly lower than that of today. These results appear consistent with previous studies on the late Pliocene floras in western Yunnan based on the coexistence approach (CA), and further suggest that there was a slightly warmer and much wetter climate during the late Pliocene than the present climate in western Yunnan. We conclude that the significant change of the monsoonal climate might have been resulted from the continuous uplift of mountains in western
\end{abstract}

Yunnan, as well as the intensification of the eastern Asian winter monsoon, both occurring concurrently in the postPliocene period.

\section{Introduction}

The modern Asian monsoon system is divided into the East Asian monsoon and the South Asian (Indian) monsoon (Molnar et al., 2010). Although they differ in precipitation terms, both are characterized by wet summers and dry winters (B. Wang, 2006). Approximately $60 \%$ of the world's population lives in the regions directly affected by the monsoon system, and therefore its fluctuation can greatly impact human activities worldwide as well as the local economy (B. Wang, 2006). The Asian monsoon has attracted great attention on its evolution, variability and forcing mechanisms (Sun and Wang, 2005; Wang et al., 2008; Han et al., 2012). While most work has focused on short-term fluctuations in monsoon behavior, study of the variations in the Asian monsoon in deep time is crucial to contextualize and understand the driving mechanisms underpinning monsoon changes. 
Western Yunnan, located at the southeastern boundary of the Qinghai-Tibet Plateau, uniquely experiences both the East Asian monsoon and the Indian monsoon (Y. Wang, 2006). The uplift and east-west extension of the QinghaiTibet Plateau has created a series of north-south oriented mountains such as Mt. Gaoligong and $\mathrm{Mt}$. $\mathrm{Nu}$ in western Yunnan (Ge and Li, 1999). These high mountains form geographical barriers for the convergence of these two monsoons (Hao et al., 2008) and result in a special regional monsoonal climate (Kou et al., 2006). Consequently, western Yunnan is an ideal region for exploring the evolution of the Asian monsoon climate in deep time. Fossil floral assemblages have been widely used as a proxy for paleoclimate reconstructions due to their direct interaction with the past surrounding environment (Wolfe, 1979, 1993; Mosbrugger and Utescher, 1997; Greenwood, 2005; Jordan, 2011). Thus, the abundance of Neogene floras in western Yunnan (Writing Group of Cenozoic Plants of China (WGCPC), 1978; Bureau of Geology and Mineral Resources of Yunnan Province (BGMRYP), 1990; Ge and Li, 1999) provides important materials for understanding the evolution of monsoonal climate.

The Pliocene is a key period for the global climate change with a transition from the warmer Miocene to the cooler Pleistocene (McKay et al., 2012). However, our understanding of the Pliocene climate in the Qinghai-Tibetan Plateau is poor. Although paleoclimates derived from several Pliocene floras in western Yunnan have been reconstructed and have provided important information on the character of the monsoon during the Pliocene (Xu et al., 2004; Yao et al., 2012; Table S1 in the Supplement), most of these paleoclimatic studies of the Pliocene floras are based on the coexistence approach (CA) by using one type of fossil material, namely palynological material (Kou et al., 2006). The principle of $\mathrm{CA}$ is based on the coexistence interval for each climate parameter of the nearest living relatives of every taxon in the flora (Mosbrugger and Utescher, 1997). Although CA clearly produces coherent climate trends that match other proxies such as those based on isotopes (Mosbrugger et al., 2005), the climatic range encompassed by the coexistence interval can be large in some circumstances, and when this occurs, the resolution of the technique appears low. An alternative approach is based on the leaf physiognomic spectrum displayed by leaves of woody dicots (Wolfe, 1993; Greenwood, 2005). Methods of this kind only need to classify fossil leaves in a flora into morphotypes without taxonomic identification (Wolfe, 1993). The Tuantian flora, being on the western side of Mt. Gaoligong and Mt. Nu, is the only Pliocene fossil flora in western Yunnan with paleoclimate reconstructions based on leaf physiognomy (Xie et al., 2012; Fig. 1).

Here, we examine the late Pliocene Longmen flora on the eastern side of Mt. Gaoligong and Mt. Nu in western Yunnan. The aims of this paper are (1) to reconstruct quantitatively the paleoclimate by using leaf-physiognomy-based methods and recently developed calibration datasets, (2) to compare our results with previous results calculated by taxa based CA in late Pliocene floras of western Yunnan, and (3) to discuss the evolution of the Asian monsoonal climate of Yunnan.

\section{Materials and methods}

\subsection{Geological setting}

The fossil site is located in Longmen Village, Yongping County, western Yunnan Province $\left(25^{\circ} 30^{\prime} 48^{\prime \prime} \mathrm{N}\right.$, $99^{\circ} 31^{\prime} 11^{\prime \prime} \mathrm{E}$; Fig. 1). Being at the southeastern boundary of the Qinghai-Tibet Plateau, western Yunnan has numerous Neogene coal-bearing basins created by the uplift of the Qinghai-Tibet Plateau (Ge and Li, 1999), and several fossil floras have been reported from these basins (Tao and Kong, 1973; Xie, 2007; Su, 2010). The sediment of Longmen in this study belongs to the Sanying Formation (Ge and $\mathrm{Li}$, 1999), which is assigned to the late Pliocene based on several lines of evidence, such as local geological structure (Compiling Group of the Regional Stratigraphic Table of Yunnan (CGRSTY), 1978; BGMRYP, 1990), stratigraphic correlations (Ge and Li, 1999), and fossil record (Tao and Kong, 1973; WGCPC, 1978; Zong et al., 1996; Su et al., 2011). Like other paleofloras uncovered from the Sanying Formation (Tao and Kong, 1973; Tao, 1986; Zhang, 1997), the evergreen sclerophyllous oak (Quercus sect. Heterobalanus) appears the most abundant in the Longmen flora ( $\mathrm{Su}, 2010)$.

The Sanying Formation in Longmen Village is composed of two units (Bureau of Geology of Yunnan Province (BGYP), 1979). Fossil leaves in this study were collected from the top part of the upper unit. Local stratigraphy has been discussed in Su et al. (2011).

\subsection{Materials}

Several fossil species such as Litsea sp. and the evergreen sclerophyllous oak from Longmen Village were first reported by the BGYP (1979). Subsequently, Zhou (1992) studied the morphology of fossil leaves in the evergreen sclerophyllous oaks uncovered from Longmen Village. During our field work from 2008 to 2010, more than 2000 pieces of specimens have been collected ( $\mathrm{Su}, 2010)$. Among them, one taxon has been anatomically studied, i.e., Drynaria callispora (Polypodiaceae; Su et al., 2011).

Among the collected specimens from the Longmen flora, fossil leaves of woody dicotyledonous species were classified into 22 morphotypes based on leaf morphological characters such as leaf shape, margin form, and the venation (Figs. S1S3 in the Supplement). All specimens are deposited in the Paleobotany Laboratory, Xishuangbanna Tropical Botanical Garden, Chinese Academy of Sciences. 


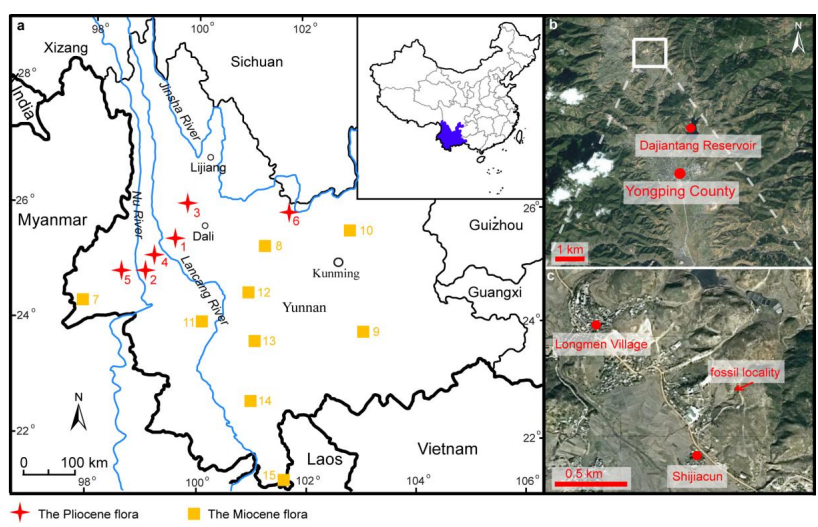

Fig. 1. Maps showing fossil localities of this study and floras with quantitative paleoclimate reconstructions. Information on fossil localities and reconstructed climates are detailed in Table S1 in the Supplement. (a) (1) Longmen, Yongping (this study); (2) Longling (Xu et al., 2004; Kou et al., 2006); (3) Liantie, Eryuan (Kou et al., 2006); (4) Yangyi, Baoshan (Kou et al., 2006); (5) Tuantian, Tengchong (Xie et al., 2012); (6) Yuanmou (Yao et al., 2012); (7) Longchuan (Zhao et al., 2004); (8) Lühe, Chuxiong (Xu et al., 2008); (9) Xiaolongtan, Kaiyuan (Xia et al., 2009; Jacques et al., 2011a); (10) Xianfeng, Xundian (Xing et al., 2012); (11) Bangmai, Lincang (Jacques et al., 2011a, b); (12) Jingdong (Zhang et al., 2012); (13) Zhenyuan (Zhang et al., 2012); (14) Jinghong (Zhang et al., 2012); and (15) Mengla (Zhang et al., 2012). (b and c): fossil locality of this study.

\subsection{Methods}

Two leaf-physiognomy-based methods were applied, namely leaf margin analysis (LMA) and Climate Leaf Analysis Multivariate Program (CLAMP). LMA is a simple way of estimating a single climate variable, namely the mean annual temperature (MAT) (Wing and Greenwood, 1993), whereas CLAMP is used routinely to calculate 11 temperature and precipitation related parameters (Wolfe, 1993). Even though the mechanism of leaf physiognomy in response to climate is still under suspicion (Little et al., 2010), both methods are still quite robust in paleoclimate reconstructions (Spicer and Yang, 2010; Peppe et al., 2011). In this study, we did not use any linear regressions to calculate the paleoprecipitation, because none of existing linear regressions could be applied for Chinese paleofloras (Su et al., 2013). For a close comparison, we also recalculated the paleoclimate of the late Pliocene Tuantian flora in western Yunnan from a published account of Xie et al. (2012; site 5 in Fig. 1) using the same calibration dataset in the present study.

\subsubsection{Leaf margin analysis}

LMA is a method based on the single linear regression between the proportion of entire leaves in woody dicots within a flora and mean annual temperature (MAT) (Wolfe, 1993). However, many studies indicate that this correlation shows regional variations worldwide (Gregory-Wodzicki, 2000; Spicer et al., 2004; Adams et al., 2008; Su et al., 2010; Royer et al., 2012). Here we use the equation based on the Chinese dataset (Su et al., 2010) and the standard error of estimated MAT (SE) follows Miller et al. (2006).

$\operatorname{MAT}\left({ }^{\circ} \mathrm{C}\right)=1.038+27.6 \times P$

(Su et al., 2010)

$\mathrm{SE}=b \times \sqrt{[1+\varphi(n-1) p(1-p)] \times \frac{p(1-p)}{n}}$

(Miller et al., 2006)

$b$ is the slope in the equation, here $27.6 ; \varphi$ is the overdispersion factor with the value of 0.052 from Miller et al. (2006); $p$ is the proportion of woody dicots with untoothed leaves; and $n$ is the total number of woody dicots in a flora.

\subsubsection{Climate Leaf Analysis Multivariate Program}

CLAMP is a multivariate method based on canonical correspondence analysis (CCA). In CLAMP, 31 leaf character states and 11 climate parameters are derived for samples from modern forests to form the calibration dataset; more than two hundred samples are available online now (http:// clamp.ibcas.ac.cn). In this study, we use the PhysgAsial calibration dataset (Jacques et al., 2011b), which supplements the core CLAMP Physg3br dataset with 45 modern Chinese sites. This calibration gives better precipitation estimates for China compared to older calibrations (Jacques et al., 2011b). We scored each leaf character of every morphotype from the Longmen flora by following the definitions on leaf characters on the CLAMP website (http://clamp.ibcas.ac.cn; Table 1). CCA was performed by using the software CANOCO 4.5 (Plant Research International, Wageningen, the Netherlands).

\subsubsection{The monsoon intensity index (MSI)}

Several indices have been defined to evaluate the intensity of the monsoon (Liu and Yin, 2002; van Dam, 2006; Liu et al., 2011; Xing et al., 2012). However, most indices could not be estimated in this study because the parameters in these indices are not directly available from either LMA or CLAMP. As the monsoon plays the role of the "engine" for the transportation of moisture, the precipitation pattern around a year is closely associated to the intensity of monsoon (B. Wang, 2006). Herein, we use the equation proposed by Xing et al. (2012) to calculate MSIs of the Longmen flora and the Tuantian flora in western Yunnan based on the three precipitation parameters reconstructed by CLAMP:

MSI $=(3$ WET $-3 \mathrm{DRY}) \cdot 100 / \mathrm{GSP}$

(Xing et al., 2012).

MSI is the intensity of monsoon climate with a higher value of MSI meaning a bigger difference of precipitation in seasonality and therefore indicating a stronger monsoon climate 
Table 1. Percentages of 31 leaf characters in the Longmen flora.

\begin{tabular}{llr}
\hline & Leaf character & Percentage (\%) \\
\hline Lobed & Lobed & 0.0 \\
Teeth of the leaf & No teeth & 59.1 \\
& Teeth regular & 38.6 \\
& Teeth close & 2.3 \\
& Teeth round & 18.2 \\
& Teeth acute & 22.7 \\
& Teeth compound & 4.5 \\
Size of the leaf & Nanophyll & 0.0 \\
& Leptophyll I & 0.0 \\
& Leptophyll II & 0.0 \\
& Microphyll I & 10.2 \\
& Microphyll II & 37.5 \\
& Microphyll III & 28.4 \\
Apex of the leaf & Mesophyll I & 17.0 \\
& Mesophyll II & 4.5 \\
& Mesophyll III & 2.3 \\
& Apex emarginate & 0.0 \\
Apex round & 28.9 \\
Base of the leaf & Apex acute & 44.7 \\
& Apex attenuate & 26.3 \\
Length to width ratio of the leaf & Base cordate & 11.1 \\
& Base round & 13.5 \\
& Base acute & 75.4 \\
& L:W $<1: 1$ & 2.3 \\
& L:W 1-2:1 & 12.9 \\
& L:W 2-3:1 & 60.6 \\
& L:W 3-4:1 & 19.7 \\
& L:W $>$ 4:1 & 4.5 \\
& Obovate & 4.5 \\
& Elliptic & 4.5 \\
\hline & Ovate & \\
& & \\
& &
\end{tabular}

(Xing et al., 2012). GSP is growing season precipitation (precipitation during months with mean monthly temperature being more than $10^{\circ} \mathrm{C}$ ). $3 \mathrm{WET}$ is the precipitation during the 3 consecutive wettest months. $3 \mathrm{DRY}$ is the precipitation during the 3 consecutive driest months.

\section{Results}

\subsection{LMA}

In the Longmen flora, the proportion of untoothed leaf taxa in 22 woody dicotyledonous species is $59.1 \%$. Thus, the MAT of the Longmen flora resolves as $17.4 \pm 3.3^{\circ} \mathrm{C}$.

\subsection{CLAMP}

By using the CLAMP calibration dataset (PhysgAsia1), the Longmen flora plots inside the physiognomic ordination space, and it resides within the cloud of modern Chinese samples (Fig. 2), which indicates that PhysgAsia1 is suitable for paleoclimate estimation of the Longmen flora. For temperature related parameters, those of the Longmen flora seem comparable with the present conditions (Table 2). For example, MAT and cold month mean temperature (CMMT) of the Longmen flora are $17.4 \pm 1.3{ }^{\circ} \mathrm{C}$ and $8.9 \pm 2.6^{\circ} \mathrm{C}$, respectively. The modern values for these parameters at Yongping are $15.9^{\circ} \mathrm{C}$ and $8.2^{\circ} \mathrm{C}$, respectively. The length of the growing season (months with temperature $>10^{\circ} \mathrm{C}$, GROWSEAS) is similar to that of the present with $9.3 \pm 0.7$ months being predicted for the Longmen flora compared to 10 months at present. However, the warm month mean temperature (WMMT) of the Longmen flora is estimated to have been much higher than nowadays.

Unlike the temperature variables, the difference between the late Pliocene and modern precipitation parameters in Longmen appears quite significant (Table 2). The largest difference for a precipitation related parameter is that of 3DRY, the predicted value for the Longmen flora is about three times higher than that of the present day, with $184.5 \pm 41.2 \mathrm{~mm}$ and $69.5 \mathrm{~mm}$, respectively. The GSP of the Longmen flora is nearly twice as high as that nowadays, with $1735.5 \pm$ $217.7 \mathrm{~mm}$ and $986.9 \mathrm{~mm}$, respectively. Both 3WET and relative humidity $(\mathrm{RH})$ estimates for the Longmen flora are higher than the present-day values.

\subsection{MSI}

The MSI of the Longmen flora is 35.5, whereas the MSI of Yongping County at present is 55.4 (Table 2).

\section{Discussion}

\subsection{Warmer temperature during the late Pliocene}

For the Longmen flora, LMA and CLAMP both give consistent results for MATs with estimated values $17.4 \pm 3.3^{\circ} \mathrm{C}$ and $17.4 \pm 1.3^{\circ} \mathrm{C}$, respectively. Both values are about $1.5^{\circ} \mathrm{C}$ higher than the present MAT. LMA is based on the single linear regression between leaf margin and MAT (Wolfe, 1979; Wing and Greenwood, 1993), whereas CLAMP is a multivariate method with 31 leaf characters included (Wolfe, 1993). Therefore, the results of these two methods are independent from each other (Spicer et al., 2009). These higher Pliocene temperatures are also found at Tuantian, which is approximately $100 \mathrm{~km}$ southwest of the Longmen flora (Table 2). These results combined both show that the MAT in western Yunnan during the late Pliocene was slightly higher than that of today. Meanwhile, CMMT stayed similar between the late Pliocene and the present day.

It is interesting to note that WMMT shows a dramatic difference with a temperature $4.4^{\circ} \mathrm{C}$ higher in the late Pliocene than that of today in Yongping. Similarly, WMMT of the Tuantian flora is $24.3 \pm 1.5^{\circ} \mathrm{C}$, comparing to $19.8^{\circ} \mathrm{C}$ at present (Table 2). The significant decrease of WMMT to today's values between the late Pliocene and now might be related to an increase in altitudes in western Yunnan. Previous studies based on both palynological data (Kou et al., 2006) and plant megafossils (Xie et al., 2012) also concluded a similar pattern of temperature and supported that the altitude of western Yunnan during the late Pliocene might not have been as 

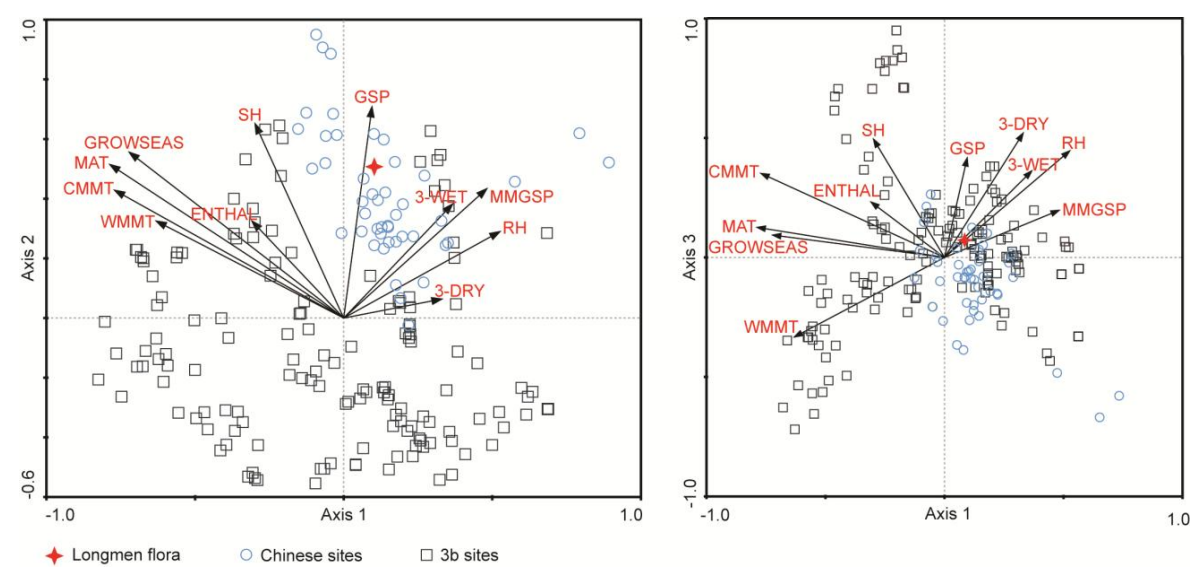

Fig. 2. Position of the Longmen flora in the physiognomic space of the calibrated CLAMP dataset - PhysgAsia1.

Table 2. Comparisons on climatic parameters between the late Pliocene and the present day in Longmen and Tuantian. For LMA, the equation proposed by Su et al. (2010) was applied and the standard errors followed Miller et al. (2006). For CLAMP, a newly updated dataset, PhysgAsia1 (Jacques et al., 2011b), was used. Leaf physiognomic data of the late Pliocene Tuantian flora were from Xie et al. (2012). The present climate data were from Yunnan Provincial Meteorological Bureau (YPMB, 1984). MAT = mean annual temperature; WMMT = warm month mean temperature; CMMT = cold month mean temperature; LGS = length of the growing season; GSP=growing season precipitation (precipitation during months with mean monthly temperature being more than $10^{\circ} \mathrm{C}$ ); $\mathrm{MMGSP}=$ mean monthly growing season precipitation; $3 \mathrm{WET}=$ precipitation during the 3 consecutive wettest months; $3 \mathrm{DRY}=$ precipitation during the 3 consecutive driest months; $\mathrm{RH}=$ relative humidity; $\mathrm{SH}=$ specific humidity; and ENTHAL = enthalpy.

\begin{tabular}{|c|c|c|c|c|c|c|}
\hline & \multicolumn{3}{|c|}{ Longmen, Yongping } & \multicolumn{3}{|c|}{ Tuantian, Tengchong } \\
\hline & LMA & CLAMP & Present & LMA & CLAMP & Present \\
\hline MAT $\left({ }^{\circ} \mathrm{C}\right)$ & $17.4 \pm 3.3$ & $17.4 \pm 1.3$ & 15.9 & $18.7 \pm 2.6$ & $15.3 \pm 1.3$ & 14.9 \\
\hline WMMT $\left({ }^{\circ} \mathrm{C}\right)$ & & $25.8 \pm 1.5$ & 21.4 & & $24.3 \pm 1.5$ & 19.8 \\
\hline $\mathrm{CMMT}\left({ }^{\circ} \mathrm{C}\right)$ & & $8.9 \pm 2.6$ & 8.2 & & $7.7 \pm 2.6$ & 7.6 \\
\hline GROWSEAS (months) & & $9.3 \pm 0.7$ & 10 & & $8.1 \pm 0.7$ & 9 \\
\hline $\mathrm{GSP}(\mathrm{mm})$ & & $1735.5 \pm 217.7$ & 986.9 & & $1625.7 \pm 217.7$ & 1381.1 \\
\hline MMGSP (mm) & & $187.6 \pm 25.3$ & 98.7 & & $186.8 \pm 25.3$ & 153.5 \\
\hline $3 \mathrm{WET}(\mathrm{mm})$ & & $800.3 \pm 139$ & 588.6 & & $787.4 \pm 139$ & 790 \\
\hline 3DRY (mm) & & $184.5 \pm 41.2$ & 69.5 & & $209.9 \pm 41.2$ & 111.6 \\
\hline $\mathrm{RH}(\%)$ & & $81.1 \pm 6$ & 75 & & $81.6 \pm 6$ & 79 \\
\hline $\mathrm{SH}(\%)$ & & $11.1 \pm 1.2$ & & & $10.3 \pm 1.2$ & \\
\hline ENTHAL $\left(\mathrm{kJ} \mathrm{kg}^{-1}\right)$ & & $334.4 \pm 5.4$ & & & $329.2 \pm 5.4$ & \\
\hline MSI & & 35.5 & 52.6 & & 35.5 & 49.1 \\
\hline
\end{tabular}

high as the present day. This conclusion is proved by other evidence, such as testate amoebae (Yang et al., 2006) and sedimentological analysis (Xie et al., 2012). Altitude correlates negatively with temperature (Y. Wang, 2006). Therefore, a lower WMMT is observed nowadays. Meanwhile, much heavier precipitation during the late Pliocene (Table 2) means that when the wet and warm airflow in summer forms the rain, and heat releases to the atmosphere, a higher temperature could be observed.

On the contrary, CMMT stayed similar between the late Pliocene and the present day. During the Late Pliocene, even the increase of altitude could decrease the temperature, and the winter monsoon brings the cold airflow from Siberia; however, CMMT happens in the dry winter with fewer clouds, and the land surface could absorb plenty of heat energy from the solar radiation. Consequently, the solar radiation compensates for the decrease of temperature caused by both a higher altitude and cold airflow from Siberia in winter. If the winter of the present day in Yongping is wet, there should be a lower CMMT. Guilin City, being at a lower altitude with a similar latitude to Yongping, experiences a wetter winter with 3DRY at $183.6 \mathrm{~mm}$. CMMT in Guilin is $7.8^{\circ} \mathrm{C}$ nowadays, compared to $8.2^{\circ} \mathrm{C}$ in Yongping (China Meteorological Data Sharing Service System (CMDSSS), http://cdc.cma.gov.cn, restriction on access to registers).

In this study, results of leaf physiognomic methods are consistent with results of the coexistence approach (CA). The Longling flora, at about $120 \mathrm{~km}$ southwest to the Longmen 

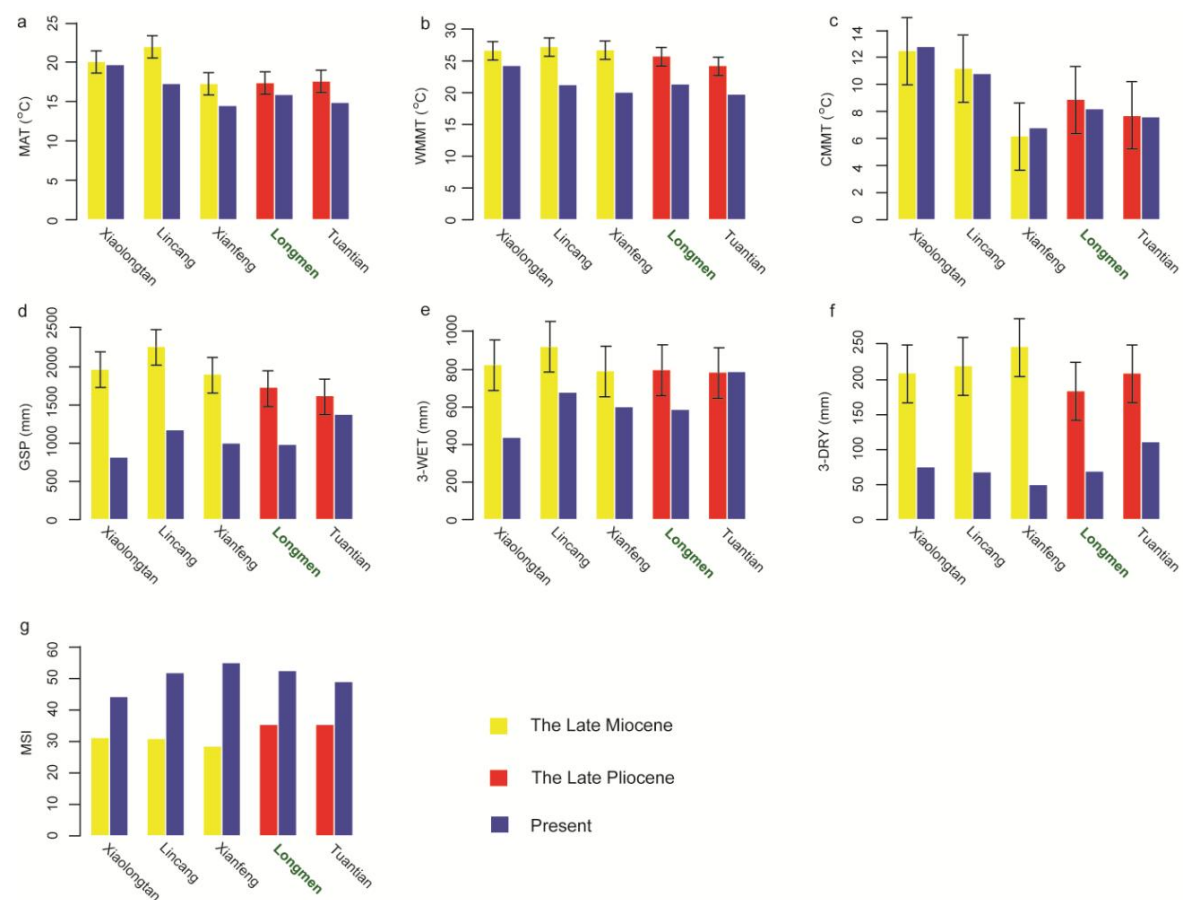

Fig. 3. Comparisons on climatic parameters among the late Miocene, the late Pliocene and the present day in Yunnan. Climatic data of the late Miocene and the late Pliocene floras are from the calibrated CLAMP dataset (PhysgAsia1) (see more details in Table S1 in the Supplement). Climatic data of the present day are from Yunnan Meteorological Bureau (1984).

flora, was studied using CA (Kou et al., 2006; Table S1 in the Supplement). MAT of the Longling flora was reconstructed to have been $18.6-22.1^{\circ} \mathrm{C}$ compared to $15.0^{\circ} \mathrm{C}$ at present. Therefore, all results based on different approaches indicate a higher temperature during the late Pliocene than at present in western Yunnan. One exception is the late Pliocene Wanbao flora in central Yunnan: a cooler climate during the late Pliocene was proposed, which might be due to the local tectonic change, forming a dry, hot valley nowadays (Yao et al., 2012).

These higher MAT and WMMT are also observed from the late Miocene floras (Table S1 in the Supplement), for example, the Xiaolongtan flora from southeastern Yunnan (Xia et al., 2009), the Lincang flora from southwestern Yunnan (Jacques et al., 2011a), and the Xianfeng flora from central Yunnan (Plate II; Xing et al., 2012), based on different methods, namely, CA, LMA and CLAMP. Results of all methods show a slight decrease of MATs between the late Miocene and the present (Table S1 in the Supplement). Moreover, the significantly higher WMMT during the late Miocene (Xu et al., 2008), is similar to the trend of WMMT cooling from the late Pliocene to today, as shown in this study.

Overall, the cooling trend from the late Miocene to present in Yunnan Province (Fig. 3) is similar to the trend of global cooling since the late Miocene (Zachos et al., 2001). The lower temperature in western Yunnan at present might be also associated with regional uplift (Kou et al., 2006), leading to the higher altitude and cooler temperature.

\subsection{Geographical precipitation pattern}

Paleoclimate reconstructions show that the precipitation during the late Pliocene was greater than that at present in western Yunnan (Fig. 3). GSPs between the late Pliocene and nowadays are comparable, because the length of the growing season (mean monthly temperature higher than $10^{\circ} \mathrm{C}$, GROWSEAS) in the late Pliocene Longmen flora is $9.3 \pm 0.7$ months and GROWSEAS of the present day is 10 months. For the Longmen flora, GSP is $1735.5 \pm 217.7 \mathrm{~mm}$, nearly twice as high as that in the present day (Table 2). As far as the wet season is concerned, 3WET is $800.3 \pm 139.0 \mathrm{~mm}$ in the Longmen flora, whereas this value is $588.6 \mathrm{~mm}$ in Yongping County today (Table 2). A similar drying is seen in the dry season. 3DRY decreases sharply from $184.5 \pm 41.2 \mathrm{~mm}$ in the Longmen flora to $69.5 \mathrm{~mm}$ in Yongping County today. Conditions wetter than now are also observed in the late Pliocene Tuantian flora; the GSP in the Tuantian flora is $1625.7 \pm 217.7 \mathrm{~mm}$ compared to $1381.1 \mathrm{~mm}$ in the present day. Meanwhile, precipitation during the three driest consecutive months (3DRY) in the present day is only half of that during the late Pliocene. However, no drying trend is seen in the wet season because the late Pliocene and modern values are similar. In this study, we could not compare the precipitation values estimated by CLAMP and CA, simply because the precipitation coexistence intervals in CA are wide in previous studies with focuses on paleoclimate reconstructions of the late Pliocene floras in western Yunnan (Xu et al., 2004; 


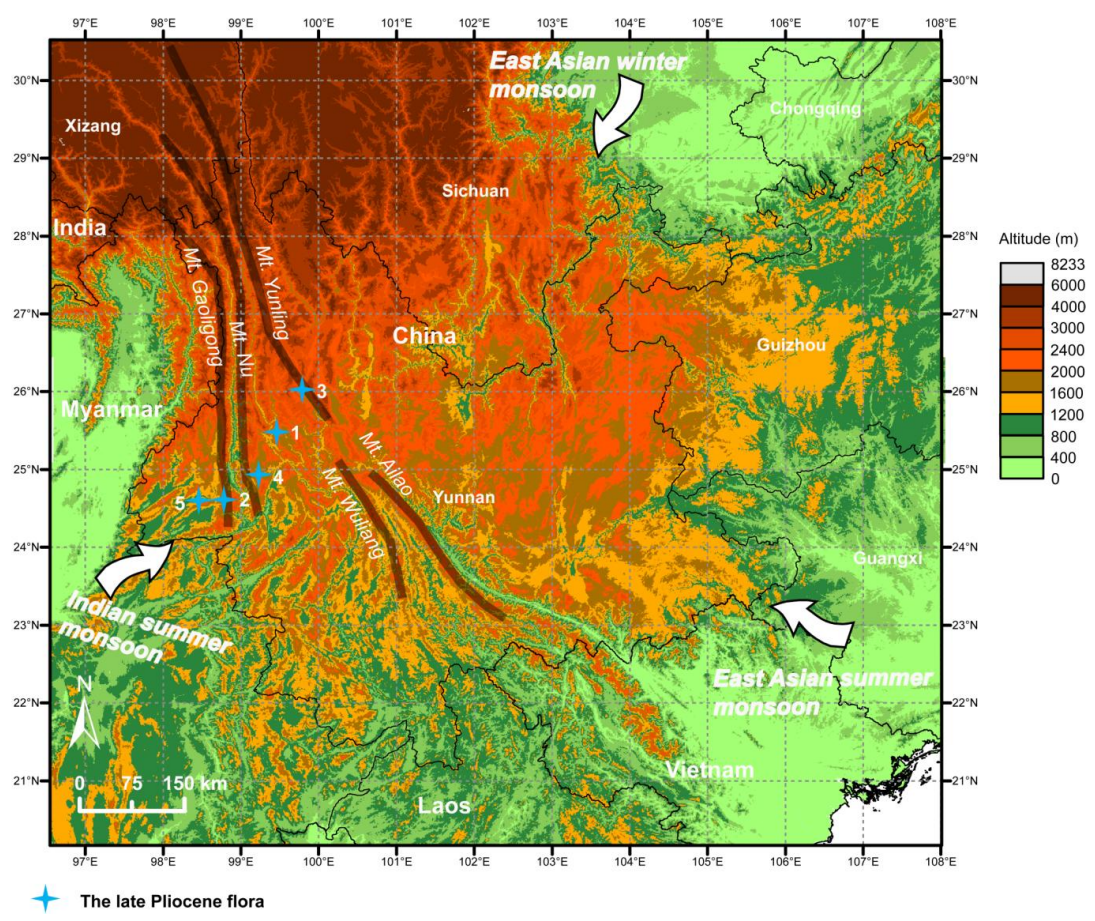

Fig. 4. The Asian monsoon system in Yunnan nowadays and the late Pliocene floras in western Yunnan. (1) Longmen, Yongping; (2) Longling; (3) Liantie, Eryuan; (4) Yangyi, Baoshan; (5) Tuantian, Tengchong. Detailed information on each flora is in Table 2 and Table S1 in the Supplement.

Kou et al., 2006), and the observed modern rainfall values are within the reconstructed intervals for the paleoprecipitation parameters (Table S1 in the Supplement).

The Longmen flora is located on the eastern side of Mt. Gaoligong and Mt. Nu, whereas the Tuantian flora is in the western side (Fig. 4). Today, both fossil localities are largely influenced by the Asian monsoon, which is characterized by a wet summer and a dry winter, and a series of northsouth oriented mountains in western Yunnan such as Mt. Gaoligong and Mt. Nu play an important role in determining moisture distribution. For example, precipitation on the western slope of Mt. Gaoligong is significantly higher than that on the eastern slope (B. Wang, 2006). During the late Pliocene, 3WETs in both Longmen flora and Tuantian flora are quite similar to each other (Table 2), and indicate a different pattern of moisture distribution and a possibly different topography.

We also notice that the precipitation of the late Pliocene Longling flora is lower than the present day (Kou et al., 2006). Longling is on the western slope of Mt. Gaoligong; the Indian summer monsoon with plenty of moisture is blocked by Mt. Gaoligong and forms heavy rain there (Fig. 4). A lower altitude of the Gaoligong Mountains during the late Pliocene could not block such high moisture on the western slope, leading to lower precipitation.

\subsection{The evolution of the Asian monsoon in western Yunnan}

This study indicates that the Asian monsoon during the late Pliocene is not as strong as at present day in western Yunnan. According to the MSI proposed by Xing et al. (2012), the intensity of the monsoon in both the Longmen flora and the Tuantian flora are lower than those of the present day (Table 2). In both floras, 3DRYs contribute to the difference of MSI between the late Pliocene and the present day. For 3DRYs, the Longmen flora and the Tuantian flora are $184.5 \pm 41.2 \mathrm{~mm}$ and $209.9 \pm 41.2 \mathrm{~mm}$, respectively, compared to $69.5 \mathrm{~mm}$ and $111.6 \mathrm{~mm}$ at present.

The MSI during the late Miocene was slightly lower than that during the late Pliocene in Yunnan (Fig. 3). MSIs of the Xiaolongtan flora, the Lincang flora and the Xianfeng flora are 31.3, 31.0 and 28.6, respectively. The lower MSIs during the late Miocene are mainly due to the higher GSP and 3DRY (Xing et al., 2012). The GSPs of all three late Miocene floras estimated by CLAMP are higher than the two late Pliocene floras. It indicates that in Yunnan there was an amplification of the Asian monsoon from the late Miocene to the late Pliocene, and a significant intensification of the Asian monsoon from the late Pliocene to the present. A Quaternary pollen record from Heqing in northwestern Yunnan further supports this conclusion (Xiao et al., 2010). 


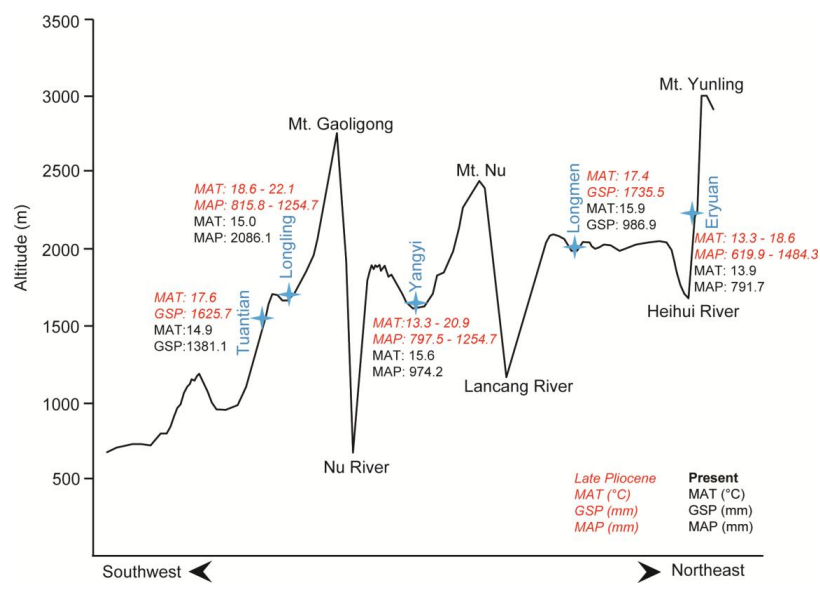

Fig. 5. Spatial comparison on temperature and precipitation between the late Pliocene and nowadays in western Yunnan (modified from Kou et al., 2006). Climatic data correspond to Table S1 in the Supplement.

However, the MSI could not distinguish the East Asian monsoon from the Indian monsoon, which both impact western Yunnan. The evolution of both monsoon systems could be explored further by examining the distribution of precipitation throughout the year.

Very interestingly, both GSP and 3WET in Yongping decrease more than those in Tengchong from the late Pliocene to the present day (Fig. 3). Today, during the summer the Indian monsoon affects Tengchong because it is situated on the western side of Gaoligong and $\mathrm{Nu}$ mountains (Fig. 5), but it barely reaches Yongping because it is on the eastern side (Fig. 5). Judging from the similar GSPs and 3WETs exhibited by the Longmen flora and Tuantian flora during the late Pliocene, Mt. Gaoligong and Mt. Nu may not have acted as such a strong barrier to monsoonal air flow. The simplest way by which this may have happened is that it was lower than now, and this interpretation is evidenced by previous studies (Fan et al., 2006; Kou et al., 2006; Yang et al., 2006; Xie et al., 2012).

As far as 3DRY is concerned, it shows the greatest decrease among all these precipitation parameters over time (Fig. 3), and it indicates the significant intensification of the Asian winter monsoon since the Pliocene. Our finding is supported by studies on loess sediments in northwestern China (An et al., 2001; Xiong et al., 2003). This intensification of the East Asian winter monsoon is interpreted to be associated with the development of the Northern Hemisphere ice sheet at high latitudes since the late Pliocene, which lead to the onset of Northern Hemisphere glaciation and the strengthening of a drier airflow from the Siberian High (Meyers and Hinnov, 2010). The dry airflow may have penetrated to some parts of western Yunnan such as Yongping along lower parts of the predominantly north-south alignment of the mountains, creating much drier winters at present than in the past (Fig. 5).

\section{Conclusions}

In this study, we used methods based on the relationship between leaf physiognomy and climate to quantitatively reconstruct the paleoclimate of the late Pliocene Longmen flora in western Yunnan. In combination with results of previous paleoclimatic studies, we conclude that:

1. Both temperature and precipitation in the late Miocene and the Pliocene of Yunnan are higher than at the present day. As temperature related parameters are concerned, MAT and CMMT decreased slightly, and WMMT decreased significantly from the late Pliocene to nowadays. All precipitation related parameters are much lower at present than those during the late Pliocene.

2. The uplift of a series of mountains such as Mt. Gaoligong and $\mathrm{Mt}$. $\mathrm{Nu}$ since the late Pliocene contributes to the creation of the modern spatial pattern of precipitation in western Yunnan.

3. In Yunnan, the Asian monsoon intensified slightly from the late Miocene to the late Pliocene, and strengthened significantly from the late Pliocene to the present day. A significant intensification of the East Asian winter monsoon in western Yunnan occurred during the Quaternary, leading to a much drier winter today than in the Neogene.

\section{Supplementary material related to this article is available online at: http://www.clim-past.net/9/1911/ 2013/cp-9-1911-2013-supplement.pdf.}

Acknowledgements. We thank W.-T. Yu, Y. Yang, G.-F. Li and F.-M. Zhang for their assistance in fossil collections, and A. Bruch and V. Teodoridis for many constructive suggestions. This work is supported by National Natural Science Foundation of China (No. 41030212 to ZKZ, No. 31100166 to TS, No. 41272007 to FMBJ), the 973 Project (No. 2012CB821900 to ZKZ), the Foundation of the State Key Laboratory of Paleobiology and Stratigraphy, Nanjing Institute of Geology and Paleontology, Chinese Academy of Sciences (No. 123106 to TS), the West Light Foundation of the Chinese Academy of Sciences (to TS), the CAS 135 program (XTBG-F01 to ZKZ), a CAS Senior Visiting Professorship (2009S1-20) to R.A. Spicer, as well as US NSF (No. EAR-0746105 to YSL).

Edited by: A. Haywood 


\section{References}

Adams, J. M., Green, W. A., and Zhang, Y.: Leaf margins and temperature in the North American flora: Recalibrating the paleoclimatic thermometer, Global Planet. Change, 60, 523-534, 2008.

An, Z.-S., Kutzbach, J. E., Prell, W. L., and Porter, S. C.: Evolution of Asian monsoons and phased uplift of the Himalaya-Tibetan plateau since Late Miocene times, Nature, 411, 62-66, 2001.

Bureau of Geology and Mineral Resources of Yunnan Province (BGMRYP): Regional geology of Yunnan Province, Geological Publishing House, Beijing, 1990 (in Chinese).

Bureau of Geology of Yunnan Province (BGYP): Regional geological survey report (geological part), Bureau of Geology of Yunnan Province, Kunming, 1979 (in Chinese).

Compiling Group of the Regional Stratigraphic Table of Yunnan (CGRSTY): Regional stratigraphic table of southwestern China: Yunnan Volume, Geological Publishing House, Beijing, 1978 (in Chinese).

Fan, C., Wang, G., Wang, S.-F., and Wang, E.: Structural interpretation of extensional deformation along the Dali fault system, southeastern margin of the Tibetan plateau, Int. Geol. Rev., 48, 287-310, 2006.

Ge, H.-R. and Li, D.-Y.: Cenozoic coal-bearing basins and coalforming regularity in western Yunnan, Yunnan Science and Technology Press, Kunming, 1999 (in Chinese with English abstract).

Greenwood, D. R.: Leaf form and the reconstruction of past climates, New Phytol., 166, 355-357, 2005.

Gregory-Wodzicki, K. M.: Relationships between leaf morphology and climate, Bolivia: implications for estimating paleoclimate from fossil floras, Paleobiology, 26, 668-688, 2000.

Han, W.-X., Fang, X.-M., and Berger, A.: Tibet forcing of midPleistocene synchronous enhancement of East Asian winter and summer monsoons revealed by Chinese loess record, Quaternary Res., 78, 174-184, 2012.

Hao, C.-Y., Wu, S.-H., and Li, S.-C.: Study on the method of areal differentiation based on SOFM, Prog. Geogr., 27, 121-127, 2008 (in Chinese with English abstract).

Jacques, F. M. B., Guo, S.-X., Su, T., Xing, Y.-W., Huang, Y.-J., Liu, Y.-S., Ferguson, D. K., and Zhou, Z.-K.: Quantitative reconstruction of the late Miocene monsoon climates of southwest China: A case study of the Lincang flora from Yunnan Province, Paleogeogr. Paleocl., 304, 318-327, 2011a.

Jacques, F. M. B., Su, T., Spicer, R. A., Xing, Y.-W., Huang, Y.-J., Wang, W.-M., and Zhou, Z.-K.: Leaf physiognomy and climate: Are monsoon systems different?, Global Planet. Change, 76, 56$62,2011 b$

Jordan, G. J.: A critical framework for the assessment of biological palaeoproxies: predicting past climate and levels of atmospheric $\mathrm{CO}^{2}$ from fossil leaves, New Phytol., 192, 29-44, 2011.

Kou, X.-Y., Ferguson, D. K., Xu, J.-X., Wang, Y.-F., and Li, C.S.: The reconstruction of paleovegetation and paleoclimate in the late Pliocene of West Yunnan, China, Climatic Change, 77, 431448, 2006.

Little, S. A., Kembel, S. W., and Wilf, P.: Paleotemperature proxies from leaf fossils reinterpreted in light of evolutionary history, PLoS One, 5, e15161, doi:10.1371/journal.pone.0015161, 2010.

Liu, X. and Yin, Z.-Y.: Sensitivity of East Asian monsoon climate to the uplift of the Tibetan Plateau, Paleogeogr. Paleocl., 183, 223-245, 2002.
Liu, Y.-S., Utescher, T., Zhou, Z.-K., and Sun, B.-N.: The evolution of Miocene climates in North China: Preliminary results of quantitative reconstructions from plant fossil records, Paleogeogr. $\mathrm{Pa}-$ leocl., 304, 308-317, 2011.

McKay, R., Naish, T., Carter, L., Riesselman, C., Dunbar, R., Sjunneskog, C., Winter, D., Sangiorgi, F., Warren, C., Pagani, M., Schouten, S., Willmott, V., Levy, R., DeConto, R., and Powell, R. D.: Antarctic and Southern Ocean influences on late Pliocene global cooling, P. Natl. Acad. Sci., 109, 6423-6428, 2012.

Meyers, S. R. and Hinnov, L. A.: Northern Hemisphere glaciation and the evolution of Plio-Pleistocene climate noise, Paleoceanography, 25, PA3207, doi:10.1029/2009PA001834, 2010.

Miller, I. M., Brandon, M. T., and Hickey, L. J.: Using leaf margin analysis to estimate the mid-Cretaceous (Albian) paleolatitude of the Baja BC block, Earth Planet. Sc. Lett., 245, 95-114, 2006.

Molnar, P., Boos, W. R., and Battisti, D. S.: Orographic controls on climate and paleoclimate of Asia: thermal and mechanical roles for the Tibetan Plateau, Annu. Rev. Earth Planet. Sc., 38, 77-102, 2010.

Mosbrugger, V. and Utescher, T.: The coexistence approach - a method for quantitative reconstructions of Tertiary terrestrial palaeoclimate data using plant fossils, Paleogeogr. Paleocl., 134, 61-86, 1997.

Mosbrugger, V., Utescher, T., and Dilcher, D. L.: Cenozoic continental climatic evolution of Central Europe, P. Natl. Acad. Sci., 102, 14964-14969, 2005.

Peppe, D. J., Royer, D. L., Cariglino, B., Oliver, S. Y., Newman, S., Leight, E., Enikolopov, G., Fernandez-Burgos, M., Herrera, F., Adams, J. M., Correa, E., Currano, E. D., Erickson, J. M., Hinojosa, L. F., Hoganson, J. W., Iglesias, A., Jaramillo, C. A., Johnson, K. R., Jordan, G. J., Kraft, N. J. B., Lovelock, E. C., Lusk, C. H., Niinemets, Ü., Peñuelas, J., Rapson, G., Wing, S. L., and Wright, I. J.: Sensitivity of leaf size and shape to climate: global patterns and paleoclimatic applications, New Phytol., 190, 724-739, 2011.

Royer, D. L., Peppe, D. J., Wheeler, E. A., and Niinemets, Ü.: Roles of climate and functional traits in controlling toothed vs. untoothed leaf margins, Am. J. Bot., 99, 915-922, 2012.

Spicer, R. A. and Yang, J.: Quantification of uncertainties in fossil leaf paleoaltimetry: Does leaf size matter?, Tectonics, 29, TC6001, doi:10.1029/2010TC002741, 2010.

Spicer, R. A., Herman, A. B., and Kennedy, E. M.: Foliar physiognomic record of climatic conditions during dormancy: Climate Leaf Analysis Multivariate Program (CLAMP) and the cold month mean temperature, J. Geol., 112, 685-702, 2004.

Spicer, R. A., Valdes, P. J., Spicer, T. E. V., Craggs, H. J., Srivastava, G., Mehrotra, R. C., and Yang, J.: New developments in CLAMP: Calibration using global gridded meteorological data, Paleogeogr. Paleocl., 283, 91-98, 2009.

Su, T.: On the establishment of the leaf physiognomy - climate model and a study of the late Pliocene Yangjie flora, Southwest China, Ph.D. dissertation, Graduate University of the Chinese Academy of Sciences, 2010 (in Chinese with English abstract).

Su, T., Xing, Y.-W., Liu, Y.-S., Jacques, F. M. B., Chen, W.-Y., Huang, Y.-J., and Zhou, Z.-K.: Leaf margin analysis: A new equation from humid to mesic forests in China, Palaios, 25, 234238, 2010.

Su, T., Jacques, F. M. B., Liu, Y.-S., Xiang, J.-Y., Xing, Y.-W., Huang, Y.-J., and Zhou, Z.-K.: A new Drynaria (Polypodiaceae) 
from the Upper Pliocene of Southwest China, Rev. Palaeobot. Palyno., 164, 132-142, 2011.

Su, T., Spicer, R. A., Liu, Y.-S., Huang, Y.-J., Xing, Y.-W., Jacques, F. M. B., Chen, W.-Y., and Zhou, Z.-K.: Regional constraints on leaf physiognomy and precipitation regression models: A case study from China, Bull. Geosci., 88, 595-608, 2013.

Sun, X.-J. and Wang, P.-X.: How old is the Asian monsoon system? - Palaeobotanical records from China, Paleogeogr. Paleocl., 222, 181-222, 2005.

Tao, J.-R.: Neogene flora of Lanping and its significance in middle watershed of Selween-Mekong-Yantze Rivers, in: Hengduan Mountain investigation special, Science and Technology Publishing House, Beijing, 1986 (in Chinese).

Tao, J.-R. and Kong, Z.-C.: The fossil florule and sporo-pollen assemblage of the Shang-In Coal series of Erhyuan, Yunnan, Acta Bot. Sin., 15, 120-126, 1973 (in Chinese with English abstract).

van Dam, J. A.: Geographic and temporal patterns in the late Neogene (12-3 Ma) aridification of Europe: The use of small mammals as paleoprecipitation proxies, Paleogeogr. Paleocl., 238, 190-218, 2006.

Wang, B.: The Asian monsoon, Springer Praxis Books, Springer, Berlin, Heidelberg, 2006.

Wang, Y.: Yunnan mountain climate, Yunnan Science and Technology Press, Kunming, 2006 (in Chinese).

Wang, Y.-J., Cheng, H., Edwards, R. L., Kong, X.-G., Shao, X.-H., Chen, S.-T., Wu, J.-Y., Jiang, X.-Y., Wang, X.-F., and An, Z.-S.: Millennial- and orbital-scale changes in the East Asian monsoon over the past 224,000 years, Nature, 451, 1090-1093, 2008.

Wing, S. L. and Greenwood, D. R.: Fossils and fossil climate: The case for equable continental interiors in the Eocene, Philos. T. Roy. Soc., 341, 243-252, 1993.

Wolfe, J. A.: Temperature parameters of humid to mesic forests of eastern Asia, compared to Australasia and the Northern Hemisphere, Geological Survey Professional Paper 1106, 1979.

Wolfe, J. A.: A method of obtaining climatic parameters from leaf assemblages, United States government printing office, Washington, 1993.

Writing Group of Cenozoic Plants of China (WGCPC): Cenozoic plants from China, fossil plants of China (Vol. 3.), Science Press, Beijing, 1978 (in Chinese).

Xia, K., Su, T., Liu, Y.-S., Xing, Y.-W., Jacques, F. M. B., and Zhou, Z.-K.: Quantitative climate reconstructions of the late Miocene Xiaolongtan megaflora from Yunnan, southwest China, Paleogeogr. Paleocl., 276, 80-86, 2009.

Xiao, X.-Y., Shen, J., Wang, S. M., Xiao, H.-F., and Tong, G.-B.: The variation of the southwest monsoon from the high resolution pollen record in Heqing Basin, Yunnan Province, China for the last 2.78 Ma, Paleogeogr. Paleocl., 287, 45-57, 2010.

Xie, S.-P.: Numerical taxonomy of winged fruits and paleoenvironmental reconstruction based on angiosperm leaves from the Neogene of West Yunnan, Ph.D. dissertation, Lanzhou University, 2007 (in Chinese with English abstract).
Xie, S.-P., Sun, B.-N., Wu, J.-Y., Lin, Z.-C., Yan, D.-F., and Xiao, L.: Palaeodimatic estimates for the late Pliocene based on leaf physiognomy from western Yunnan, China, Turk. J. Earth Sci., 21, 251-261, 2012.

Xing, Y.-W., Utescher, T., Jacques, F. M. B., Su, T., Liu, Y.-S., Huang, Y.-J., and Zhou, Z.-K.: Paleoclimatic estimation reveals a weak winter monsoon in southwestern China during the late Miocene: Evidence from plant macrofossils, Paleogeogr. Paleocl., 358-360, 19-26, 2012.

Xiong, S.-F., Ding, Z.-L., Jiang, W.-Y., Yang, S.-L., and Liu, T.-S.: Initial intensification of East Asian winter monsoon at about 2.75 Ma as seen in the Chinese aeolian loess-red clay deposit, Geophys. Res. Lett., 30, 1524, doi:10.1029/2003GL017059, 2003.

Xu, J.-X., Ferguson, D. K., Li, C.-S., Wang, Y.-F., and Du, N.-Q.: Climatic and ecological implications of late Pliocene palynoflora from Longling, Yunnan, China, Quaternary Int., 117, 91-103, 2004.

Xu, J.-X., Ferguson, D. K., Li, C.-S., and Wang, Y.-F.: Late Miocene vegetation and climate of the Lühe region in Yunnan, southwestern China, Rev. Palaeobot. Palyno., 148, 36-59, 2008.

Yang, J., Zhang, W.-J., Feng, W.-S., and Shen, Y.-F.: Geographical distribution of testate amoebae in Tibet and northwestern Yunnan and their relationships with climate, Hydrobiologia, 559, 297304, 2006.

Yao, Y.-F., Bruch, A. A., Cheng, Y.-M., Mosbrugger, V., Wang, Y.F., and Li, C.-S.: Monsoon versus uplift in southwestern China late Pliocene climate in Yuanmou Basin, Yunnan, PLoS One, 7, e37760, doi:10.1371/journal.pone.0037760, 2012.

Yunnan Provincial Meteorological Bureau (YPMB): Agricultural climate database of Yunnan, Yunnan People's Press, Kunming, 1984 (in Chinese).

Zachos, J., Pagani, M., Sloan, L., Thomas, E., and Billups, K.: Trends, rhythms, and aberrations in global climate $65 \mathrm{Ma}$ to present, Science, 292, 686-693, 2001.

Zhang, Y.-Z.: Lithostratigraphy in Yunnan Province, China University of Geosciences Press, Wuhan, 1997 (in Chinese).

Zhang, Q.-Q., Ferguson, D. K., Mosbrugger, V., Wang, Y.-F., and Li, C.-S.: Vegetation and climatic changes of SW China in response to the uplift of Tibetan Plateau, Paleogeogr. Paleocl., 363-364, 23-36, 2012.

Zhao, L.-C., Wang, Y.-F., Liu, C.-J., and Li, C.-S.: Climatic implications of fruit and seed assemblage from Miocene of Yunnan, southwestern China, Quaternary Int., 117, 81-89, 2004.

Zhou, Z.-K.: A taxonomical revision of fossil evergreen sclerophyllous oaks from China, Acta Phytotaxon. Sin., 34, 954-961, 1992 (in Chinese with English abstract).

Zong, G.-F., Chen, W.-Y., Huang, X.-S., and Xu, Q.-Q.: Cenozoic mammals and environment of Hengduan Mountains region, China Ocean Press, Beijing, 1996 (in Chinese). 